\title{
Swami Vivekananda's Conception of the Universe with Reference to the CREATION IS A FAÇADE/ PROJECTION/ REFLECTION Conceptual Metaphor: A Non-dualistic Cognitive Semantic Study in Light of the Vedanta
}

\section{Suren Naicker}

\section{Abstract}

This study applies conceptual metaphor theory (CMT) to the Complete Works of Swami Vivekananda, a well-known and influential Indian saint. Analysed from a cognitive semantic perspective, this study sheds light on an aspect of the Vedanta philosophy, one of the six schools of orthodox thought in the Indian system, and demonstrates Vivekananda's predilection and preference for a non-dualistic interpretation of the tradition, known as Advaita ("nondual') Vedanta. An in-depth analysis of an underlying conceptual metaphor is expounded upon, and various well-known texts from the non-dualistic tradition are alluded to. A particular version of the theory is used in this study, and presented in a novel way using a table to illustrate the underlying conceptual mapping that is said to take place in the aggregate of Vivekananda's teachings on matters pertaining to this topic. The article concludes with idea that Vivekananda did indeed see a non-dualistic interpretation of Hindu philosophy, applied here to the concept of $\mathrm{CREATION}^{1}$ as a metaphysical

\footnotetext{
${ }^{1}$ As is convention in the field of Cognitive Semantics, upper case is used to indicate conceptual domains. Titles and non-English words are written in italics, and without diacritics, for easy reading; derived words, 'Vedic', will not be italicised, whereas Vedas will be. When quoting, terms are cited as in the original.
} 
philosophical exposition in the theme, as the acme of Indian philosophy, and perhaps also as the starting point for praxis within the tradition.

Keywords: cognitive linguistics, conceptual metaphor theory, Vedanta, Hindu philosophy, Vivekananda

\section{Introduction}

This study is an in-depth analysis of a pervasive conceptual metaphor which runs through a nine-volume corpus like an elaborate conceit. Using Conceptual Metaphor Theory (CMT) as a framework to mine Swami Vivekananda's Complete Works, means that this is essentially a Cognitive Semantic study, although no theoretical claims are being made here regarding the theory, except to make the fiat assumption that this theory has sufficient explanatory power shed some light on the conceptual metaphor employed. Because this particular metaphor is a key leitmotif in the said text, especial attention is given to it in the current study. Understanding this metaphor offers a key insight into Vivekananda's philosophy, although any study of this kind offers but a glimpse, given that his teachings covered several domains, including social philosophy and religious theory.

The first section will begin with a summary of the Vedanta, which falls under the Astika ('orthodox') tradition. Orthodoxy, in this context, means that the philosophy is premised on the authority of the Vedas, which is a group of ancient texts, believed to have been divinely revealed to certain sages during their meditative states. There are six such schools of orthodox Hindu thought, and six schools which do not fall into that category, and are referred to as Nastika ('unorthodox'), which simply means that these traditions are not based on the authority of the Vedas. For a more detailed overview, cf. Akliykar (2017), as even a concise overview will not be possible in article-format as this will not do justice. After briefly explaining what Vedanta is, a specific school of thought known as Advaita Vedanta will be outlined, followed by an introduction to Swami Vivekananda, which ends with a quote illustrating his allegiance to the Advaita ('non-dual') school of Vedantic philosophy.

Thereafter, the theoretical framework will be introduced. CMT is an influential school of thought within the field of Cognitive Linguistics, and in 
fact has been said to be the most 'important term'2 in Cognitive Linguistics. This could be, in part, that key exponent of CMT has also been referred to as the 'founder of Cognitive Linguistics' Pinker (2007: 245). Although this is debatable, what is less controversial is the fact that CMT was one of the first influential theories within the field of Cognitive Linguistics, and the term 'cognitive linguistics' was coined by the said linguist in Lakoff (1987).

\section{Overview of Vedanta}

An ancient sage by the name of Vyasa is said to be the founder of the Vedanta school of thought. The Vedanta system is based on the writings to be found in the Upanishads, and, as explained earlier, it contains the doctrines set forth in the 'closing chapters of the Vedas', which is literally what the Upanishads are (Sivananda 1977: 270).

There are several books which 'go by the name Upanishad, although the orthodox tradition accepts only a handful of them' (Harshananda 2011: 66). Vivekananda concurs, saying that 'the Upanishads are many, and said to be one hundred and eight', but also adds that in some of these texts, like 'the Allopanishad', God is praised from an Islamic perspective as 'Allah', and the Islamic prophet, 'Mohammed is called the Rajasulla' (CW-3: 190). In his classic translation of the Upanishads, Radhakrishnan (1994) selected eighteen as being the principal Upanishadic texts. Within the Divine Life Society ${ }^{3}$, a neoHindu organisation much like the Ramakrishna Math and Mission, 13 of these Upanishads are considered the 'major ones' (Krishnananda 1973: 87), omitting the Subala, Jabala, Paingala, Kaivalya and Vajrasucika Upanishads, which Radhakrishnan ${ }^{4}$ included. Within the Ramakrishna Mission, 11 of these are considered the principal Upanishads, omitting the Subala Upanishad. Sankara (see next section below) himself wrote commentaries on ten of these, and this forms the basis of what is now known as the Advaita Vedanta (Harshananda 2011: 71).

${ }^{2}$ http://scodis.com/for-students/glossary/conceptual-metaphor/

3 A neo-Hindu organisation founded in 1936 by a well-known saint, Swami Sivananda Saraswathi, with branches all over the world, including South Africa.

${ }^{4}$ Sarvepalli Radhakrishnan (1888-1975) was an influential Indian philosopher and statesman who served as the first vice-president of India (1952-1962), and the second president of India (1962-1967). 
Vivekananda said that 'the Vedanta philosophy, as it is generally called at the present day, really comprises all the various sects that now exist in India' (CW-1: 357). He later goes on to say (in the same discourse, entitled The Vedanta Philosophy), that Vedanta really has become one and the same as Hinduism itself. The Upanishads, then, from a practical purview, form the scriptures of the Hindus, and all systems of philosophy that are orthodox have to take them as their foundation, according to Vivekananda. Vivekananda also pointed out that 'the Upanishads are our Bible', when addressing a group of American devotees in California (CW-9: 240). Others have also referred to the Upanishads as 'the most important portion of the Vedas' (Sivananda 1977: 9). The most well-known commentators on the Vedanta are Sankara, Ramanuja and Madhva. They founded the schools known as Advaita ('non-dualism'), Visishtadvaita ('qualified non-dualism'), and Dvaita ('dualism') Vedanta. These three divisions are assumed here simply because these are the subschools which Vivekananda expounded upon in his various teachings (Harshananda 2011).

The word Vedanta can be broken up into two constituent words: veda ('knowledge') and anta ('end of'). Hence, we could take the word 'Vedanta' to literally refer to the end section of the Vedas, namely the Upanishads, or some scholars like to give it a more poetic connotation, and explain it as the culmination of all others philosophies within the Hindu tradition.

One of the distinguishing features of Vedantic philosophy, according to Vivekananda, is the idea that 'nothing in the universe is permanent', in contradistinction to the Mimamsa. Furthermore, he adds that 'Satan did not have much chance in India' (CW-1: 496), meaning that the belief in a devil which functions as the antithesis of God did not and still does not make sense to the Eastern mind. Nature comprises two components: akasha ('fine substance', where this connotes 'inert', or 'insentient'), and the other is called prana ('animating force', with the connotation of sentience, being the force behind the akasha). All material substances manifest as a result of akashic actions, some finer (like the mind) and some more material (like solid objects). Both these aspects (matter and spirit) pervade the entire cosmos. (The Sanskrit terms for 'matter' and 'spirit' are prakriti and purusha respectively, and this is what is being referred to here.) One can imagine akasha as the ocean, and prana as the force which gives form to 'portions' of this otherwise formless mass, creating something like blocks of ice in various shapes and animating it. In fact, 'the whole universe is a combination of prana and akasha' (CW-1: 223). 
Vivekananda was not averse to other schools of Vedanta, but especially advocated for the non-dualistic school as the pinnacle and final goal of intellectual and spiritual life, which was partly why he founded the Advaita Ashram in Mayavati, India. The next section provides an overview of Advaita Vedanta, which is the school of thought Vivekananda was advocating when employing the conceptual metaphor analysed in this study.

\section{The Non-dualism of Sankara (Advaita Vedanta)}

Although the exact date of when he lived is not known, the 'dates assigned to him vary from the sixth century BC to the eighth century AD' (Mukhyananda 2006: 3). Sankara was said to have been born as a boon to his parents, Shivaguru and Aryamba, who prayed to Lord Shiva to grant them a son, after ardent supplications for such. The Lord was said to have appeared to Shivaguru, and asked him to choose 'between an all-knowing, scholarly and virtuous son' whose life would be short-lived, or between a mediocre son who would have a long life, 'but without any special quality' (Rukmani 1994: 18). Shivaguru chose the former. It is said that Sankara was a precocious child, and 'at the age of eight he mastered' all the Vedas, and wrote his commentary on the Brahmasutras 'at the age of sixteen' (Rukmani 1994: 18). During his life, spanning thirty-two years, he travelled the length and breadth of India, giving public lectures, partaking in debates with scholars and priests, invariably defeating them, and winning them over as followers or disciples. He also wrote his commentaries, and established four Maths ('monasteries') in the north, south, east and west of India, each one dedicated to keeping the integrity of one division of the Vedas intact. These were established at "cardinal points of India to serve as headquarters for carrying on the work in the four zones: at Puri in the East of Orissa, at Dwaraka in the West of Gujarat, at Badrinath in the North in the Himalayas, and at Sringeri in the South in Karnataka' (Mukhyananda 2006: 11). This has been achieved by committing to memory the contents, and passing it down to resident monks in an unbroken chain of succession.

Sankara also formalised the institution of monk-hood, and established the ten orders of monk-hood (Mahadevan 1957). This is known as the Dasanamis ('ten orders'). Traditionally, to become a swami, one must 'receive initiation from men who themselves are swamis' (Yogananda 2000: 223), and there is an 'unbroken line of saintly teachers' from Sankara's time to date (Yogananda 2000: 222). Even though Ramakrishna did not initiate his 
disciples formally (Nikhilananda 1974: 384), many would agree with Sivananda that the 'Sannyasins [monks] of the Ramakrishna Mission belong to the order of Sri Sankara', since they 'they have the name Puri' (Sivananda 1977: 192) and thus align them with the principles of Advaita Vedanta.

In addition to his commentaries on the Upanishads, Sankara also wrote commentaries on the Bhagavad Gita, and the Brahmasutras, and collectively these are known as the Prasthanatrayi, which have become 'the pillars of' the Advaita philosophy (Rukmani 1994: 44).

However, Vivekananda pointed out that 'most of the authorities cited [by Sankara] are from the Upanishads', and notes later on that this is what gives the Advaita Vedanta an upper hand over the other schools, who 'take refuge more and more' in the smritis (CW-3: 128). He does not say whether by 'other schools' he means within the Vedanta, or within the broader context of the six orthodox schools.

Sankara's main idea can be summarised as follows: 'Brahman alone is real; this world is only an illusory appearance. The jiva ['individual soul'] is verily Brahman, and is not different from Him' (Harshananda 2011: 85). He categorises Brahman ('Absolute Reality') into two, Para-Brahman ('Great Absolute Reality'), and Apara-Brahman ('Lower Absolute Reality'), where the former refers to the underlying Consciousness which manifests the illusion of the world, the latter refers to the name and form superimposed on Brahman. This multiplicity of names and forms is referred to as vivarta vada ('apparent modification'), as opposed to vikara vada ('permanent modification'), both of which arise as a result of avidya ('ignorance').

The universe arises partly because people superimpose their concepts onto Brahman. Mukhyananda (2006: 61 - e.i.o.) clarifies this idea by pointing out that 'we always superimpose our conceptions of the universe', based on our conceptual system, and our current state of mind.

The basic idea is thus that the universe is a false entity, manifesting as a result of maya ('illusory power'), and as such it is our duty to 'find out about its true nature', and the idea is that when we realise the world is 'false', in a sense, we will reject a life of sense-indulgence, renounce the world, and establish ourselves as one with Brahman (Mukhyananda 2006: 63). This kind of inquiry into the nature of 'Transcendental Truth' is called Brahma-vichar. Sankara established prerequisites and disciplines for the 'seeker of the Highest Truth', and this essentially comprises his teachings and methods for achieving the goal (Mukhyananda 2006: 84-85). 
The idea behind Advaita is essentially that there is One Reality, and everything else is a false superimposition on It. By the practice of viveka ('discrimination') and other such sadhanas ('spiritual practices'), one can come to realise that the ephemeral nature of the world, the human body, this earthly existence, and so on are essentially like a passing dream, and eventually come to the realisation of tat tvam asi ('That thou art'), referring to the idea that one's jiva ('individual soul') is one and the same as Brahman. As such, Sankara established 'the highest spiritual philosophy which declares the Oneness of all Existence and the Divinity of humanity' (Mukhyananda 2006: 133).

\section{Swami Vivekananda}

Vivekananda is one of the most influential modern-day Hindu scholars, and his interpretation of the ancient Hindu scriptural lore is very significant. Vivekananda's influence was part of the motivation for choosing his teachings as the empirical domain for the current study.

Swami Vivekananda was a Bengali saint, and social reformer. He was the disciple of the well-known Bengali mystic, Sri Ramakrishna. Following Sri Ramakrishna's death in 1886, Vivekananda, upon Ramakrishna's instruction, led a group of young disciples and founded what is now known as The Ramakrishna Math and Mission, 'whose wide spreading branches offer shelter and solace to millions all the world over' (Prabhananda 2009: iii). Indeed, The Ramakrishna Math and Mission has grown to become one of the biggest and most influential neo-Hindu organisations in the world. Furthermore, Vivekananda deviated from orthodoxy by starting a new order of monkhood, the Ramakrishna Order of Monks. Until this point, females were not allowed to be initiated as monks, and people of lower castes were also barred from entering monastic life. Vivekananda changed that, and many influential religious leaders after him followed suit, like Swami Sivananda, founder of the Divine Life Society, Sri Aurobindo, and Paramahamsa Yogananda. The headquarters of The Ramakrishna Math and Mission is known as Belur Math and is located in the northern region of Kolkata, India. The South African headquarters is located in Glen Anil, Durban, with various branches all over the country.

Vivekananda travelled all over India and Ceylon, as well as to many countries in the West, spreading his teachings, inspired by Sri Ramakrishna. 
After travelling throughout the West, having made more inroads in the USA than elsewhere, he was welcomed back to India 'as a national hero' (Prabhananda 2009: 231), and 'seemed like a veritable Napoleon of the spiritual world' (Prabhananda 2009: 234). Whilst in America, there were several newspaper reports of his lectures which made his efforts there known to the people of India. Regarding his life's mission in general, Vivekananda had the following to say $(\mathrm{CW}-5: 71-72)^{5}$ :

to put the Hindu ideas into English and then make out of dry philosophy and intricate mythology and queer startling psychology, a religion which shall be easy, simple, popular, and at the same time meet the requirements of the highest minds - is a task only those can understand who have attempted it. The dry, abstract Advaita must become living — poetic — in everyday life; out of hopelessly intricate mythology must come concrete moral forms; and out of bewildering Yogi-ism must come the most scientific and practical psychology and all this must be put in a form so that a child may grasp it. That is my life's work.

His teachings, made up of transcripts from his speeches on various topics, 'question and answer' sessions, letters, written texts, including poetry, prose and commentaries on various scriptures, have been compiled and published, and is known as The Complete Works of Swami Vivekananda, and this corpus constitutes the empirical of analysis for the current study, as mentioned in the beginning of this section.

\section{Theoretical framework}

Research on conceptual metaphor goes as far back as Aristotle's Poetics. Chapters 21 and 22 of the said work focus specifically on the conceptual basis of metaphor. Aristotle defines metaphor as 'the application of a strange term either transferred from the genus and applied to the species or from the species and applied to the genus, or from one species to another or else by analogy', and adds that metaphor is specifically the act of 'giving the thing a name

${ }^{5}$ For ease of reference, CW-5: 71-72 will be the format used to refer to 'Complete Works, volume 5, pages 71- 72'. 
belonging to something else, the transference being on the grounds of analogy' (Levin 1982: 24, quoting Aristotle's Poetics XXI, 1457b). Thus, Aristotle sees metaphor essentially as the process of applying concepts from one thing to another, and goes through various examples citing what we would now call mapping between the genus and species, species and genus, etc. Turner (1995: 179 - e.a.) pointed out that the claim that metaphor is conceptual in nature 'is ancient', and that Aristotle meant by transfer nothing other than 'its conceptual role', or metaphor specifically as 'motivated by conceptual relations'.

More recently, the study of metaphor can be seen as having 'three relatively unrelated 'waves of fame' in the $20^{\text {th }}$ century; the first brought about by the reflections on metaphor by Ivor A. Richards and Max Black, published between 1930 and 1960, the second instigated by Roman Jakobson's work on metaphor and metonymy, and the third, more recent one, triggered by George Lakoff and Mark Johnson's book Metaphors We Live By in the 1980s' (Nerlich $\&$ Clarke 2001: 40). However, 'work within the cognitive linguistics tradition' is 'still probably the dominant strand within metaphor research today' (Low et al. 2010: vii), hence, it is the latter that serves as the theoretical framework for the current study.

As defined conventionally within the CL paradigm, Lakoff and Johnson (1980) is taken to be the seminal text on which CMT is based. Similar to the thinkers described in the previous section, Lakoff and Johnson also assumed a conceptual basis for metaphor, which entailed cognitive mapping from one conceptual domain to another conceptual domain; more specifically, from the source to the target domain. A fundamental principle of CMT is that metaphor operates at the level of thought. Johnson (1987) took the notion of embodiment further, and showed that people think the way they do because of the contingent arrangement of the human body: because people happen to be vertical, the UP IS MORE and UP IS BETTER metaphors happen to be more prominent.

Lakoff and Turner (1989), looking mostly at poetic metaphors from modern English literature, showed that there are superordinate metaphors, under which subordinate metaphors get subsumed; the LOVE IS A JOURNEY metaphor encompasses the LOVERS ARE TRAVELLERS metaphor, for example. Lakoff, in his various subsequent works on framing, added to this a broader conceptual level, claiming that there is a generic frame into which these various metaphors slot. In the example just mentioned, one could say that this belongs to a JOURNEY frame. What the frame does, then, is to create in 
the mind certain expectations: people expect there to be a path along which the relevant people will travel, they typically expect some sort of vehicle to be used, and there is the expectation of a destination (marriage), etc. Within this frame, certain metaphors will make sense, and others will not.

Lakoff (2014) outlines the various stages that conceptual metaphor theory has been through to date, and the nuances over the last four decades pertaining to that are not important, and cannot be delved into here due to lack of space. What is important to note is the shift in cognitive science from looking at surface phenomena only, followed by an attempt the understand the underlying conceptual mechanisms behind such. Hence, linguistic metaphors are often seen as manifestations of often underlying conceptual metaphors, which is the basis for understanding the import of the various linguistic metaphors. Following a convention used by Kövecses (2010: 9-10), the source and target domains are stated at the top of each table, prior to the mappings, and the arrows indicate a one-to-one mapping of that aspect from the source domain onto a particular aspect of the target. An example of how mapping could take place between the source and target domains can be illustrated as follows with regard to the LOVE IS A JOURNEY conceptual metaphor, mentioned above:

Table 1: Mapping for LOVE IS A JOURNEY

\begin{tabular}{|l|c|l|}
\hline Source: JOURNEY & & Target: LOVE \\
\hline Travellers & $\rightarrow$ & Lovers \\
\hline Vehicle & $\rightarrow$ & The relationship \\
\hline The journey & $\rightarrow$ & Events in the relationship \\
\hline Obstacles on the road/path & $\rightarrow$ & Difficulties in the relationship \\
\hline Distance covered & $\rightarrow$ & Progress made \\
\hline Reaching destination & $\rightarrow$ & $\begin{array}{l}\text { Culmination of the relationship } \\
\text { (marriage?) }\end{array}$ \\
\hline $\begin{array}{l}\text { Decisions about which way to } \\
\text { go }\end{array}$ & $\rightarrow$ & Choices about what to do \\
\hline
\end{tabular}

As discussed above, this hypothetical conceptual mapping helps to explain why statements like This relationship is going nowhere, This is a very bumpy relationship, and so on. Various things can be said about the import of this metaphor, depending on the particular context or frame that it pertains to. 
The current study will apply this framework to Vivekananda's Complete Works, and an analysis will be done on one particular conceptual metaphor, which read like a metaphorical conceit throughout the said text. Given that this metaphor seems to pervade the entire nine volumes of the corpus, it is worth looking in detail at the import of this metaphor, and how it relates to Vivekananda's philosophy in general.

\section{Method and Analysis}

After reading through a representative sample Swami Vivekananda's Complete Works, the various linguistic metaphors that he used were noted, and categorized accordingly. Although there were many metaphors that could be categorized into various themes, the most pervasive instantiations belonged to the theme 'Mans Place in the Universe', and can be stated as: CREATION IS A FAÇADE/PROJECTION/REFLECTION.

Table 2 Tokens from CW pertaining to the CREATION IS A FAÇADE/ PROJECTION/ REFLECTION Conceptual Metaphor:

a. 'So we are in reality one with the Lord, but the reflection makes us seem many, as when the one sun reflects in a million dew-drops and seems a million tiny suns ${ }^{6}{ }(\mathrm{CW}-1: 196)$

b. 'As the one sun, reflected on various pieces of water, appears to be many, and millions of globules of water reflect so many millions of $\underline{\text { suns, }}$, and in each globule will be a perfect image of the sun, yet there is only one sun, so are all these Jivas but reflections in different minds. These different minds are like so many different globules, reflecting this one Being. God is being reflected in all these different Jivas. But a dream cannot be without a reality, and that reality is that one Infinite Existence' (CW-1: 228)

c. 'The same sun, reflected by a thousand little wavelets, will represent to us thousands of little suns' (CW-1: 284)

d. 'As when the sun shines upon millions of globules of water, upon each particle is seen a most perfect representation of the sun, so the one Soul, the one Self, the one Existence of the universe, being

${ }^{6}$ Bold underline added to emphasise words/phrases with metaphorical import. 


\begin{tabular}{|ll|}
\hline & $\begin{array}{l}\text { reflected on all these numerous globules of varying names and } \\
\text { forms, appears to be various. But it is in reality only one' (CW-2: } \\
\text { 147) }\end{array}$ \\
\hline e. 'If the sun reflects upon millions of globules of water, in each \\
globule is the form, the perfect image of the sun; but they are only \\
images, and the real sun is only one. So this apparent soul that is in \\
every one of us is only the image of God, nothing beyond that. The \\
real Being who is behind, is that one God. We are all one there' (CW- \\
2: 220) \\
\hline f. 'The sun reflected from millions of globules of water appears to be \\
millions of suns, and in each globule is a miniature picture of the \\
sun-form; so all these souls are but reflections and not real' (CW-3: 5) \\
\hline g. 'The apparent variety is but the reflection seen in time and space, as \\
we see the sun reflected in a million dewdrops, though we know \\
that the sun itself is one and not many' (CW-8: 13)
\end{tabular}

Table 3 Mapping for CREATION IS A FAÇADE/ PROJECTION/ REFLECTION

\begin{tabular}{|l|l|l|}
\hline $\begin{array}{l}\text { Source: } \\
\text { FAÇADE/PROJECTION/REFLECTION }\end{array}$ & & Target: CREATION \\
\hline Sun & $\rightarrow$ & $\begin{array}{l}\text { Underlying } \\
\text { Reality/Divine } \\
\text { Consciousness which } \\
\text { projects the universe }\end{array}$ \\
\hline Sun's reflection & $\rightarrow$ & Appearance of variety \\
\hline Dewdrops/globules/wavelets & $\rightarrow$ & $\begin{array}{l}\text { Medium through which } \\
\text { this variety is perceived }\end{array}$ \\
\hline
\end{tabular}

\section{Import of Metaphor}

The Hindu notion of the world being a manifestation of God's illusory power is made evident here. The appearance of multiplicity is due to faulty understanding, and faulty perception.

It is evident that this is a recurrent metaphor in Vivekananda's teachings, and he uses it to illustrate a very profound point, one which is the basis for all of the teachings within the Advaita Vedanta school of thought. 
Before looking at the actual meaning behind the metaphor, it is important to see how Vivekananda builds up to this conclusion. There are two categories of Vedantic texts, each with a rich, intricate history, comprising various abstruse texts, and each serving a very different purpose. One may be called the argumentative texts, and they serve to 'refute other theories' and establish the Advaita Vedanta philosophy 'through logic and argumentation', and the other 'merely state[s] the Absolute Truth with authority and do[es] not indulge in reasoning for refuting or establishing anything. They are intuitional works, whereas the former are intellectual' (Sivananda 2014). One of Vivekananda's contributions to the neo-Hindu movement, is a reconciliation of these two, since he provided the crux of the Upanishadic texts, but explicated his teachings sufficiently so as to provide an intellectual justification for its tenets. One text in the former category is known as the Drig Drishya Viveka ('On the Discrimination Between the Seer and the Seen') which will be referred to below.

One of the most startling conclusions of Advaita Vedanta is the claim that we are, in essence, Pure Consciousness, which may go by various names, including 'God', though given the dualistic connotation within the Abrahamic context, that would be a misnomer. This consciousness 'reflects' itself as the material world, which we tend to experience and mistake for reality. Actually, our experience of the world is as unreal as a dream, though whilst experiencing the dream, it feels quite real; just as one might mistake a reflection for the actual object.

The Upanishads are often found to be written in the genre of a Socratic dialogue, whereby a preceptor, mentor, or teacher of some kind instructs a student on some points of life or philosophy, generally depending on the bent of the student. In the Katha Upanishad, for example, the student, Nachiketas, approaches the Lord of Death, Yama, and confronts Him with a variety of questions regarding the nature of death, and by implication, the nature of life. The entire dialogue culminates in the conclusion that nothing in this world is real, and that our soul is immortal, and one with the Supreme Soul, and that the goal of life is to realise this. Likewise, all the Upanishads drive at the same point.

In one of the Upanishads, a similar method is followed where the question of the nature of consciousness is put forth to the teacher by asking what it is that impels the mind to think, the eyes to see, and so on. Just as by analogy one would ask what the difference is between a fan that is rotating and one that is still, the answer would have to include the fact that the one which is rotating does so by virtue of the flow of electricity, etc. Likewise, the body 
should be an inert body of mass, yet there is something animating it. The question being asked, then, is where this consciousness comes from. This is a reasonable question even in this day and age where neural firing per se cannot account for all the phenomena we experience, and cannot explain the phenomenon of free will, which must necessarily and paradoxically precede any brain activity. An in-depth discussion of this will be beyond the scope of this explanation, but the answer given in the Upanishads is that there is an underlying Consciousness which animates each and every living being. This Consciousness 'shines' through the mind and animates the body; this can be illustrated as follows:

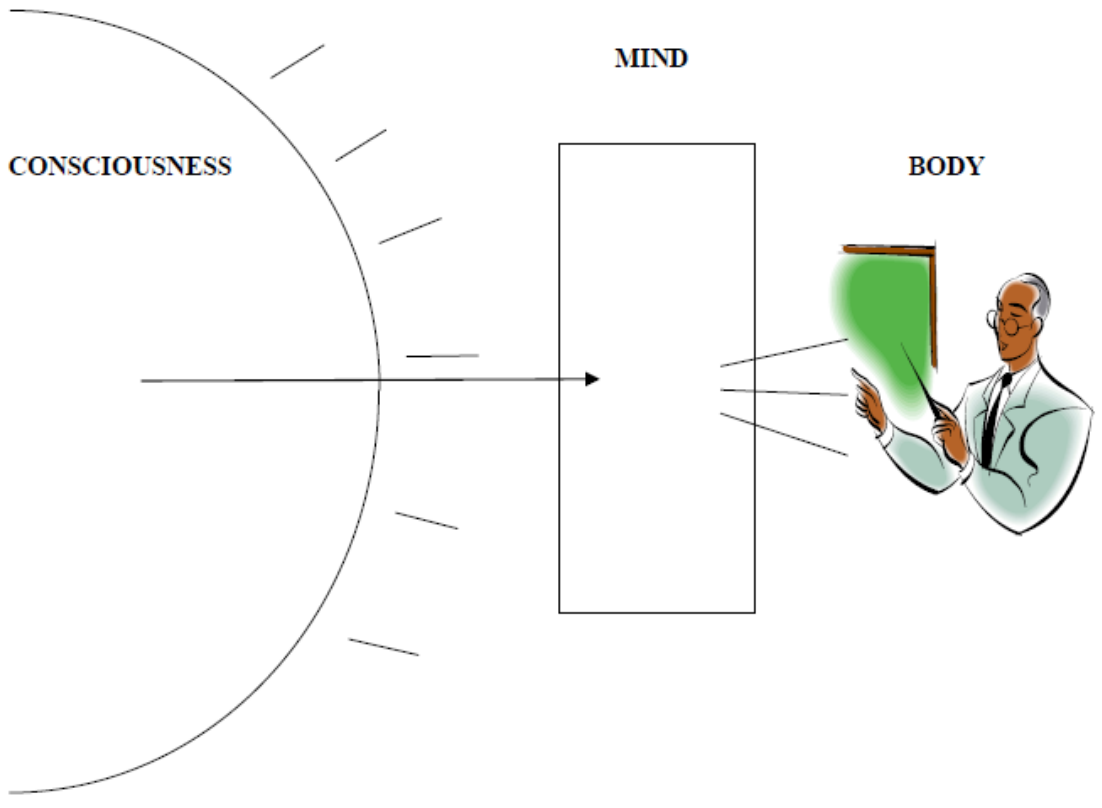

Figure 1: This diagram illustrates how the mind acts as a medium through which consciousness is 'reflected', animating (and ultimately manifesting) not just the body, but the world around it too.

Hence, Vivekananda explains that Consciousness may be understood as comprising these five qualities: 
1. It is not part of the body or the mind;

2. Despite the fact that it is apart from the body and mind, it pervades and illumines both, enabling the body to function as a conscious being, giving it an ostensibly separate identity;

3. This Consciousness is not limited by the mind or the body;

4. This Consciousness is known through the functioning of the mind and the body;

5. Without the mind and body, this Consciousness is still there, but cannot be known.

One can understand this in the context of Vivekananda's metaphor thinking of the sun's reflection in the globule of water.

Firstly, one must presuppose that the actual sun is out of one's range of vision, so all that is available is the reflection allowing one to draw abductive inferences about the nature of the actual sun. It is to be understood that the reflected sun is not part of the water droplet, but also that this water droplet is the only means we have in having some kind of access and therefore knowledge about the real sun. That being said, it is also evident that the actual sun is not a product of the reflected sun, but does nevertheless pervade and 'illumine' the water droplet. The sun is not limited or constrained in any way by the globules of water because its existence is separate. However, the clearer and larger the droplet, the clearer the reflection will be, allowing for a more accurate perception of the actual sun, meaning that one can only have knowledge of the actual sun by virtue of these drops of water, and this knowledge will necessarily be limited, but as per point number 5. above, without the water droplets as a medium, there can be no access at all. It is in this way that consciousness is a product of the body. It is this consciousness which illumines the mind and the sense organs, but the body/mind also limits one's ken. Intellectual and sensory faculties, once applied to understanding this Consciousness, can yield a limited understanding of it, but the point is that without this, Consciousness will still be there, for it is eternal, but cannot be known or appreciated.

It is this that is meant when Vivekananda urges us to see ourselves as Pure Consciousness, and therefore realise our own immortality.

Just as there are many water droplets reflecting what seems to be many suns, it is only one sun taking on many forms, which are wrongly perceived as such. This answers the question which is often asked, as to whether this Con- 
sciousness animates all sentient beings in the world: is it a 'different' Consciousness manifesting in each being, or not? As can be inferred from the analogy, it is indeed one unified Consciousness manifesting in these different beings. Chapter 13 of the well-known Hindu scripture, the Bhagavad Gita, said to be 'a commentary on the Upanishads' (CW-1: 252), answers this question in the following way: 'In all these beings, it is the One Consciousness shining through'.

Vivekananda puts forth various arguments to show that there must be an underlying, eternal Consciousness which pervades the whole of creation. The analogy used here speaks to that, and Vivekananda argues for it in various ways, in keeping with the Vedantic tradition of rigorous philosophical argumentation in defence of its tenets, much like Sankara did when he travelled the length and breadth of India propounding his Advaita Vedanta philosophy circa 1200 years ago. In the same spirit, Vivekananda is adamant about not taking things at face value, and encourages people to have a critically inquiring mind: he says that we must all have a scientific mind when it comes to religion in general, and Vedanta specifically. Data must be looked at and analysed from various angles, and goes so far as to say that Vedanta is no Vedanta if does not lead to a scientifically and intellectually justified philosophy. Furthermore, this must lead one to practically implementable, verifiable and replicable results. In this way, Vedantic inquiry should lead to 'workable hypotheses' (CW-1: 209), and since '[e]ach science must have its own methods' (CW-1: 72), he was clear about the Vedantic philosophical system being founded upon sound scientific principles, and had to be argued for in the same spirit by various philosophical, logical and scientific means, for it is only in this way that 'the Vedantic cosmology will be placed on the surest of foundations' (CW-5: 69). He further stated that he 'clearly see[s]' Vedanta's 'perfect unison with modern science' (CW-5: 69-70), and expressed his intent to write a book 'showing the harmony between Vedantic theories and modern science' (CW-5: 70), which regrettably never manifested. The point here is that Vivekananda did not merely state these metaphors expecting people to accept their import without a rigorous, sound argument to back up the philosophical imports thereof.

Another argument Vivekananda used to justify the idea that there must be a constant, unchanging Consciousness which animates and permeates the world, and obviously the beings within the world, is one based on discrimination between the subject and the object, or the knower and the known, as per the Drig Drishya Viveka, for example. This is outlined below, 
and tied in to the metaphor illustrating the philosophy thereafter.

This argument is premised on the principle that the knower, and that which is known, have to necessarily be separate. In this way, the eyes, as the means through which one comes to know the objects of the world, must necessarily be different from the object being perceived. In this way, one sees everything in the world, besides the eyes themselves. The eyes can never be used to look at themselves, but one can come to know something about the eyes through other means - by looking at it in the mirror, by looking at a photograph, by reading about what the eye in general can do, and so on.

The eyes remain constant, despite the variety of the objects being seen; this can be illustrated as follows:

\section{Eyes (subject) $\quad \rightarrow \quad$ Objects of visual perception (object)}

As mentioned, it is also possible to have some kind of meta-awareness of the eyes. In addition to doing so by various means, the mind can be used as an instrument to visualise the eyes, and also to understand it from various perspectives - how it evolved, what it means to be blind, have ideas about other peoples' eyes, etc. In this way, there is a reversal of the subject and the object, and can be illustrated as follows:

\section{Mind (subject) $\quad \rightarrow \quad$ Eyes (object)}

Here, the eyes now become the object of knowledge, and furthermore the eyes are no longer the constant factor - the mind is, and the eyes are now 'seen' in various forms, from different perspectives. So in addition to the mind becoming the knower (subject), and the eyes becoming the known (object), the subject has also 'lost' its quality of constancy, and becomes variegated and sundry; however, these are known by the same mind.

Taking this further, one can also have meta-awareness of one's own mind, and speculate about our thoughts, feelings, memories, and so on. This is why the field of psychology has evolved to what is today: an inquiry into the functioning of the human mind. Since one's speculations about the eye need not be limited to such, one can also extend the inquiry to the very nature and functioning of the mind itself: 
The mind is being used to understand itself, meaning that the mind as the subject is being used to understand the mind as an object, which violates the axiom postulated at the outset, namely that the subject and the object are to be separated, leading to an inevitable paradox. If one is to separate the subject and the object, then it would not make sense to make the mind the subject in this case, even though that is ostensibly the case:

\section{Mind (subject) $\quad \rightarrow \quad$ Mind (object)}

Following the train of thought thus far, we see that since the mind has now become the object of knowledge, there is a lacuna which needs to be filled: (subject) $\quad \rightarrow \quad$ Mind (object)

Another trend which is evident, is that the object of knowledge is variegated, whereas the subject is stable and constant. Now that the mind has become the object of knowledge, it needs a perceiving subject. Now that one sees that, there is a gap which begs an explanation. Vivekananda says that there is what the Vedantic scriptures refer to as Sakshi ('Eternal Witness'), allowing for the logical gap to be filled as follows:

\section{Sakshi (subject) $\quad \rightarrow \quad$ Mind (object)}

This Sakshi is unknowable, as it can never become the object of perception. This Witness is our true Self, and the underlying Consciousness by which we know everything else. There is a Witness behind the mind, it is who one 'really' is; in this context Vivekananda says that ' $\mathrm{t}$ ] here is really but one Self in the universe, all else is but Its manifestations' (CW-5: 274), so it is this Witness which is Pure Consciousness, and our true nature is essentially this Consciousness.

Quoting the Gita (Chapter 13), Vivekananda points out Lord Krishna's words, where He says: 'Know Me, I God am the knower in all bodies'. Essentially, what is being said here is that we are God. Advaita Vedanta leads us to this conclusion in various ways, and the Upanishads state these Truths in various ways. For example, in Chapter 6 of the Chandogya Upanishad, taken from the Sama-Veda, it is stated that Tat Tvam Asi, which means 'You are 
That'. 'You', in this context, referring to the Witness or Sakshi explicated upon above.

Getting back to the metaphor used to illustrate this, there is this one Reality, one Consciousness 'shining through' all beings, which are in effect a projection of this Consciousness. A little of this Consciousness can be understood by looking at its projection through the medium of the mind, but all these things are actually false, in a sense, and just as the water droplets are subject to evaporating into veritable nothingness, people's minds too will dissipate at death, and it should be used to try and understand as much of one's true nature as possible in this life. In this way, Vivekananda says that 'we feel the whole world' as being one with one's Self (CW-2: 229).

In Sankara's classic text, Dakshinamurthi Stotram, a similar metaphor is to be found, where he talks about the universe being like a city reflected in a mirror, where the mirror is analogous to one's mind, or consciousness. In this context, Vivekananda says that the world must be seen as a manifestation of that Consciousness we call God, and, as such, he states that 'the ideal of Vedanta is to know man as he really is, and this is its message, that if you cannot worship your brother man, the manifested God, how can you worship a God who is unmanifested?', and interprets the Biblical quote, 'If you cannot love your brother whom you have seen, how can you love God whom you have not seen?', in this context (CW-2: 173). Furthermore, Vivekananda says that '[y]ou cannot see your own face except in a mirror, and so the Self cannot see Its own nature until It is reflected, and this whole universe therefore is the Self trying to realise Itself. This reflection is thrown back first from the protoplasm, then from plants and animals, and so on and on from better and better reflectors, until the best reflector, the perfect man, is reached - just as a man who, wanting to see his face, looks first in a little pool of muddy water, and sees just an outline; then he comes to clear water, and sees a better image; then to a piece of shining metal, and sees a still better image; and at last to a looking-glass, and sees himself reflected as he is. Therefore, the perfect man is the highest reflection of that Being who is both subject and object. You now find why man instinctively worships everything, and how perfect men are instinctively worshipped as God in every country' (CW-3: 5). This idea put forth by Vivekananda can easily be tied in to biological evolution, and reconciled with a spiritual paradigm, as done by various scholars like Killingley (1990: 151), who relates Darwinian evolution to Patanjali, and Vivekananda, and states that 'the concept was used in ancient Indian thought even before Darwin'. 
The idea then is to see all beings as manifestations of God, and we will come to see the Spiritual Reality behind these manifestations as none other than God's divine play. This is why 'its nature is more reflected in some minds than in others [...] Thus it goes on, until the mind has become so purified that it reflects fully the quality of the soul; then the soul becomes liberated' (CW6: 11).

These metaphors can also be expounded upon based on the teachings of the Mandukya Upanishad, where the states of consciousness discussed above are referred to, viz. the waking, dream and dreamless sleep states, and concludes that there must be a fourth state known as Turiya, which is a state of mind where one's identity with the Sakshi is understood.

In terms of the metaphor Vivekananda uses, the actual sun would be like the state of Turiya, or the Sakshi, the human mind like the globule/water droplet, and the various reflections of the sun like the variety manifest in the universe. This is what Vivekananda means when he says that the mind affects the way we perceive the world and God, though God does not change and is not affected by the way we perceive Him or His creation: 'What you call love and fear, hatred, virtue, and vice are all reflections of the spirit; only when the reflector is base the reflection is bad' (CW-8: 103).

\section{Conclusion}

This study looked at a particular conceptual metaphor: CREATION IS A FAÇADE/ PROJECTION/ REFLECTION. Using CMT as a tool, it was shown how Vivekananda uses this as a springboard to explain a cornerstone of the non-dualistic branch of the Vedanta philosophy. He said that his goal was to make the ideas inherent in this philosophy accessible to lay-persons, and it seems that by using simple language and metaphors, he has succeeded in this endeavour, since at least a part of this hitherto rather arcane and esoteric philosophy can be explained in simple English. As discussed above, his explanations make reference to several other key Hindu texts, like Drig Drishya Viveka and the Mandukya Upanishad, texts which are rarely studied even in monastic institutions, not to mention lay persons.

It is evident that Vivekananda had a particular 'soft spot' for an Advaitic conception of his version of the Vedanta philosophy. An in-depth analysis of one of his most frequently used metaphors yields some insight into his metaphysical philosophy, and given the import and influence of his work, 
a key recommendation would be to mine his Complete Works for other metaphors that have re-shaped the way Hinduism is currently conceptualized. CMT has proven to be a powerful tool with which to analyse a large corpus like this, and various other methods can be employed to look into this important body of work from other perspectives. Computer software, for example, can be used to search for key metaphorical terms, which could lead to insights into other conceptual metaphors used. Future research could also include a comparative study between similar metaphors amongst key neo-Hindu scholars, like Radhakrishnan and Aurobindo. Of course, other influential scholars within the neo-Hindu tradition, like Paramahamsa Yogananda and Sri Aurobindo, should also be looked at, and the prediction is that metaphors similar to those analysed in this article will be found, because Vivekananda laid the philosophico-ideological foundation upon which they built - however, this is an argument for another study.

\section{References}

Akliykar, A. 2017. History and Doxography of the Philosophical Schools. In Ganeri, J. (ed.): Oxford Handbook of Indian Philosophy. Oxford: Oxford University Press.

Harshananda, S. 2011. The Six Systems of Hindu Philosophy - A Primer. Chennai: Sri Ramakrishna Math Printing Press.

Johnson, M. 1987. The Body in the Mind - The Bodily Basis of Meaning, Imagination, and Reason. Chicago: University of Chicago Press. https://doi.org/10.7208/chicago/9780226177847.001.0001

Killingley, D.H. 1990. Yoga Sutra IV 2-3 and Vivekananda's Interpretation of Evolution. Journal of Indian Philosophy 18,2: 151 - 179.

https://doi.org/10.1007/BF00240477

Kövecses, Z. 2010. Metaphor - A Practical Introduction. $2^{\text {nd }}$ Edition. Oxford: Oxford University Press.

Krishnananda, S. 1973. A Short History of Religious and Philosophic Thought in India. Divine Life Society Press: Rishikesh.

Lakoff, G. \& M. Johnson 1980. Metaphors we Live By. Chicago, IL: University of Chicago Press.

Lakoff, G. \& M. Turner 1989. More than Cool Reason: A Field Guide to Poetic Metaphor. Chicago, IL: University of Chicago Press. https://doi.org/10.7208/chicago/9780226470986.001.0001 
Lakoff, G. 2014. Mapping the Brain's Metaphor Circuitry: Metaphorical Thought in Everyday Reason. Frontiers in Human Neuroscience 8: 1 - 14. https://doi.org/10.3389/fnhum.2014.00958

Lakoff, G. 1987. Women, Fire and Dangerous Things: What Categories Reveal about the Mind. Chicago: University of Chicago Press. https://doi.org/10.7208/chicago/9780226471013.001.0001

Levin, S.R. 1982. Aristotle's Theory of Metaphor. Philosophy \& Rhetoric 15: $24-46$.

Low, G., Z. Todd, A. Deignan \& L. Cameron (eds.). 2010. Researching and Applying Metaphor in the Real World. Philadelphia, PA: John Benjamins. https://doi.org/10.1075/hcp.26

Mukhyananda, S. 2006. Sri Shankaracharya - Life and Philosophy: An Elucidative and Reconciliatory Interpretation. $4^{\text {th }}$ Edition. Kolkata: Advaita Ashrama Publication Department.

Nikhilananda, S. (tr.) 1974. The Gospel of Sri Ramakrishna. $6^{\text {th }}$ Edition. Madras: Jupiter Press.

Pinker, S. 2007. The Stuff of Thought - Language as a Window into Human Nature. New York: Penguin Books.

Prabhananda, S. 2009. The Early History of the Ramakrishna Movement. Chennai: Sri Ramakrishna Math.

Rukmani, T.S. 1994. Shankaracharya. New Delhi: Ministry of Information and Broadcasting.

Sivananda, S. 1977. All about Hinduism. Rishikesh: Divine Life Society Press. Sivananda, S. 2014. Introduction to Vedanta. Rishikesh: Divine Life Society Press.

Turner, M. 1995. As Imagination Bodies Forth the Forms of Things Unknown. Pragmatics and Cognition 3,1: 179 - 185.

Vivekananda, S. 1977. The Complete Works of Swami Vivekananda-Volumes 1 - 9. Kolkata: Mayavati Press.

Yogananda, P. 2000. Autobiography of a Yogi. Kolkata: Jaico Publishing House.

Suren Naicker Department of Linguistics and Modern Languages University of South Africa Pretoria suren1946@gmail.com 